Canadian Studies in Population, Vol. 12 (1), 1985, pp. 81-102

\title{
CHARACTERIZATION OF METROPOLITAN AND NONMETROPOLITAN OUTMIGRATION SCHEDULES OF THE CANADIAN POPULATION SYSTEM, 1971-1976
}

\author{
Kao-Lee Liaw \\ McMaster University, Hamilton, Ontario, Canada \\ and \\ D.N. Nagnur \\ Statistics Canada, Ottawa, Ontario, Canada
}

Abstract - This paper characterizes the 1971-76, sex-specific, interregional outmigration schedules of the Canadian population system with 86 age groups $(0,1,2, \ldots, 85+)$ and 24 regions (the 23 Census Metropolitan Areas in addition to the rest of Canada) by using the Rogers-Castro model. The model fits the data well. The Canadian migration pattern is shown to be similar to those of several European countries in terms of sex differences and the metropolitan versus nonmetropolitan contrast. Among the Canadian CMA's, we found large variations in migration level and in the shape of the tail part of the migration schedules. The migration schedules of many CMA's do not show a "normal" retirement peak.

Key words - Canada, metropolitan, nonmetropolitan, migration schedule 


\section{Introduction}

The typical behaviour of individuals is often closely related to their age. The importance of age is clearly illustrated by the fact that in all national populations, the fertility schedules are unimodal and positively skewed and the mortality schedules are U-shaped. The empirical regularity in the dependence of fertility and mortality on age has long been observed and successfully fitted to mathematical models (Brass, 1974; Brass and Coale, 1968; Coale and Trussell, 1974). Because of their very high levels of "goodness-of-fit", these models have been found useful by population researchers in estimating missing data, summarizing empirical schedules by a handful of parameters, identifying the major types of age patterns and even forecasting future population changes.

Realizing that in many populations, geographical mobility also depends very strongly on age, Rogers et.al. (1978), Rogers $(1978,1979)$ and Rogers and Castro (1981) formulated a migration model and fitted it to data on interregional migration in socialist as well as capitalist countries including Bulgaria, Hungary, Japan, the Netherlands, the Soviet Union, Sweden, the United Kingdom, and the United States. Their results are impressive.

The purpose of this paper is to characterize the 1971-76 interregional migration schedules of the Canadian population by using the RogersCastro model. The next section describes and explains the model. We then define the interregional population system and show how the model is fitted to the observed migration schedules. Next, we show the national pattern and compare it to those of other nations. We then look at the nonmetropolitan-to-metropolitan migration pattern, after which we examine the outmigration schedules of the three most populous metropolitan areas - Montreal, Toronto, and Vancouver. After comparing the outmigration schedules of the remaining 20 metropolitan areas, we summarize the main points of this paper.

\section{The Rogers-Castro Model}

Two important attributes of a human population are (a) the long years of childhood in which the young members of the society are economically and socially dependent and (b) the existence of the family as a basic socioeconomic unit. These attributes imply that in an in- 
dustrialized country the geographical mobility of children up to their middle teens closely resembles that of their parents.

Between the late teens and the early twenties, most people reach a "launching stage" when they decide whether to pursue higher education, seek gainful employment, form a new household and marry. A change in location is associated with these changes in lifestyle, and geographical mobility increases very rapidly in the late teens and reaches a high level in the early twenties.

The accumulation of physical assets and job seniority, the increased specialization and obsolescence in job skills, the desire to avoid frequent locational changes in the schooling of children, and perhaps also a decrease in ambition, combine to decrease geographical mobility of those between their late 20 s and their early 50 s. In a relatively wealthy country such as Canada, a significant proportion of the elderly may be able to afford to migrate to places with milder climates, more pleasant environments or lower costs of living; resulting in the so-called retirement peak during the post-labour force ages.

The Rogers-Castro model is designed to depict systematic changes in mobility of the sort described above. The model is of the form

$$
\begin{aligned}
M(x)= & A_{1} \exp \left(-\alpha_{1} x\right) \\
& +A_{2} \exp \left\{-\alpha_{2}\left(x-\mu_{2}\right)-\exp \left[-\lambda_{2}\left(x-\mu_{2}\right)\right]\right\} \\
& +A_{3} \exp \left\{-\alpha_{3}\left(x-\mu_{3}\right)-\exp \left[-\lambda_{3}\left(x-\mu_{3}\right)\right]\right\} \\
& +C
\end{aligned}
$$

where $M(x)$ is the migration rate at age $x, C$ represents a basic mobility level and is independent of age, the term beginning with $A_{1}$ represents the mobility pattern of children, and the ones beginning with $A_{2}$ and $A_{3}$ represent the mobility patterns associated with young adults and with retired adults, respectively. All parameters (the $A_{i}, \alpha_{i}, \lambda_{i}$, and $\mu_{i}$ ) are nonnegative.

The interpretation of the parameters in equation 1 is facilitated by considering the second and third terms. They are of the form

$$
f(x)=A_{i} \exp \left\{-\alpha_{i}\left(x-\mu_{i}\right)-\exp \left[-\lambda_{i}\left(x-\mu_{i}\right)\right]\right\}_{\text {for } i}=2,3
$$


The proportional change in $f(x)$ is

$$
\dot{f}(x) / f(x)=-\alpha_{i}+\lambda_{i} \exp \left[-\lambda_{i}\left(x-\mu_{i}\right)\right]
$$

With all parameters positive, the $\alpha_{i}$ are "descent parameters", and the $\lambda_{i}$ are "ascent parameters": based on the functional form, mobility cannot decrease with age if $\alpha_{i}=0$, and increase with age if $\lambda_{i}=0$. Between ages 30 and 60, $\alpha_{2}$ approximates the annual proportional rate of decrease, since the second term on the right-hand side of equation 3 is close to zero in this age range (e.g. $\lambda_{2} \exp \left[-\lambda\left(x-\mu_{2}\right)\right]<0.01$ for $\mathrm{x} \geq 30$ and typical parameter values $\lambda_{2}=0.4$ and $\mu_{2}=20$ ). However, between the midteens and the early twenties, the rate of ascent changes very rapidly with age. For example, with $\lambda_{2}=0.4, \alpha_{2}=0.1$, and $\mu_{2}=20$, the rates of ascent of ages 16,18 and 20 are $1.88,0.79$ and 0.30 , respectively (Rogers and Castro, 1981).

By setting equation 3 to zero, we see that the maximum value of $f(x)$ occurs at

$$
\tilde{x}_{i}=\mu_{i}-\left(1 / \lambda_{i}\right) \ln \left(\alpha_{i} / \lambda_{i}\right)
$$

Clearly, when the ascent and descent parameters are equal, $\mu_{i}$, the central-tendency-parameter, is the age at which $f(x)$ is maximized. However, $\alpha_{i}$ need not equal $\lambda_{i}$. Coale and McNeil (1972), who originally used equation 2 to model the age pattern of first marriages, showed that the mean age of $f(x)$ is

$$
x_{i}=\mu_{i}-\left(1 / \lambda_{i}\right) \psi\left(\alpha_{i} / \lambda_{i}\right)
$$

where $\psi=\dot{\Gamma} / \Gamma$ is the digamma function. When $\alpha_{i}=\lambda_{i},-\psi$ equals Euler's constant, which is approximately 0.5772 (Spiegel, 1963). Thus, while the parameter $\mu_{i}$ is not the mean age of $f(x)$, the important point is that the mean age varies directly with $\mu_{i}$, other things being equal.

The first term of the model, associated with child mobility, is a simple exponential function. Starting from the maximum level of $A_{1}$ at $x=0$, it decreases at a rate of $\alpha_{1}$ per year.

In summary, the parameters $A_{1}, A_{2}, A_{3}$ and $C$ fix the levels of the four components; $\alpha_{1}, \alpha_{2}$ and $\alpha_{3}$ are the descent parameters; $\lambda_{2}$ and $\lambda_{3}$ are the ascent parameters; and $\mu_{2}$ and $\mu_{3}$ are parameters of central tendency.

To assist the comparison of migration schedules in terms of the relative importance of the four components, Rogers and Castro (1981) 
recommended that the level parameters be scaled to make the gross migraproduction rate (GMR) equal to one. The resulting standardized parameters are:

$$
\tilde{A}_{i}=A_{i} / G M R
$$

and

$$
\tilde{C}=C / G M R
$$

In addition to the 11 parameters in equation 1 , several "derived" measures are useful. For example, integrating $M(x)$ through all ages, yields the GMR which shows a person's expected number of migrations from birth to the end of the life span. Other derived measures are defined later in this paper.

The Interregional Population System and the Estimation of Outmigration Schedules

We divided Canada into 23 metropolitan regions and a nonmetropolitan region. The metropolitan regions are the 1976 Census Metropolitan Areas (CMA's) and the nonmetropolitan region is the rest of Canada. Within each region, the population is disaggregated into 86 age groups $(0,1,2, \ldots, 85+)$ for each sex.

Age- and sex-specific outmigration rates were computed for each region by dividing the 1971-76 outmigrants destined to other regions by the 1971 populations of the sending region. Two data adjustments were necessary. First, for those CMA's whose boundaries changed between the 1971 and 1976 censuses, the 1971 regional populations by age and sex were made consistent with the 1976 areas. Second, migrants whose 1971 places of residence were unknown were allocated proportionately between internal and foreign origins.

Let $M(x, s, i)$ be the 1971-76 interregional outmigration rate of age $x$, sex $s$, and region $i$. Then

$$
M(x, s, i)=K(x \rightarrow x+5, s, i \rightarrow *) / K(x, s, i)
$$

where $K(x, s, i)$ is the number of individuals of age $x$, sex $s$, in region $i$ on 1 June 1971, among whom $K(x \rightarrow x+5, s, i \rightarrow *)$ were found to be residing 
in other regions in Canada on 1 June 1976. Thus, $M(x, s, i)$ are "quinquennial transition rates" defined for single-year age groups; and the average age at the time of migration is in general closer to $x+2.5$ than $x$. Since the measure contains no information about multiple migrations during the five-year period and excludes nonsurviving migrants, the sum of $M(x, s, i)$ across all age groups will be less than five times the true GMR. The pattern of the migration rates over all ages is referred to as a migration schedule.

We define also the sex-specific national migration schedules, based on

$$
M(x, s, *)=\sum_{i=1}^{24} K(x \rightarrow x+5, s, i \rightarrow *) / \sum_{i=1}^{24} K(x, s, i)
$$

From the Law of Large Numbers, we expect the national schedules to be little affected by idiosyncratic fluctuations and biases in the raw data.

The observed migration schedules which are computed from equations 8 and 9 are fitted to the Rogers-Castro model by minimizing the objective function

$$
X^{2}=\sum_{x=0}^{85+}\left\{[M(x, s, i)-M(x)]^{2} / M(x)\right\}
$$

The computations are done by a Fortran program provided by Andrei Rogers. An index of poorness-of-it, $E$, is calculated as:

$$
E=\left\{\frac{1}{86} \sum_{x=0}^{85+}|M(x, s, i)-M(x)| / \frac{1}{86} \sum_{x=0}^{85+} M(x, s, i)\right\} 100 \%
$$

$E$ is thus "the mean of absolute differences between the estimated and observed values expressed as a percentage of the observed mean" (Rogers and Castro, 1981). For simplicity, we will call $E$ the "average error." Also, the gross migraproduction rate (more precisely, this is the net migraproduction rate, because the effects of mortality have not been adjusted for) is calculated as: 


$$
G M R=\sum_{x=0}^{85} M(x) / 5
$$

for the model schedule, and

$$
G M R=\sum_{x=0}^{85} M(x, s, i) / 5
$$

for the observed schedule. Since the model is to be fitted to our quinquennial (rather than annual) data, the standardized level parameters are to be computed according to

$$
\tilde{A}_{i}=\left(A_{i} / 5\right) / G M R
$$

and

$$
\tilde{C}=(C / 5) / G M R
$$

where GMR is obtained by equation 12 .

\section{The National Pattern}

The female and male national migration schedules are shown in Figure 1. The three curves represent the observed and model migration schedules and the difference between the two. The model yields a very good fit: the average error is 2.7 per cent for females and 3.0 per cent for males. The GMR's of 1.4 for females and 1.3 for males suggest that over the course of their lives females tend to be more mobile than males. In contrast, males have been shown to be more mobile than females in interprovincial migration in Canada during the same period (Foot, 1982:68). Since the average distance of migration in our 24-region system is shorter than that of interprovincial migration, the contrast indicates the widelyobserved fact that females tend to dominate in short distance moves.

For both sexes, the quinquennial migration rate at the youngest age is approximately $A_{1}+C=13.5$ percent, which is a fairly high mobility level. The descent parameter of the young dependents is $\alpha_{1}=10$ percent for females and 11 percent for males. The minimum migration rate of the 

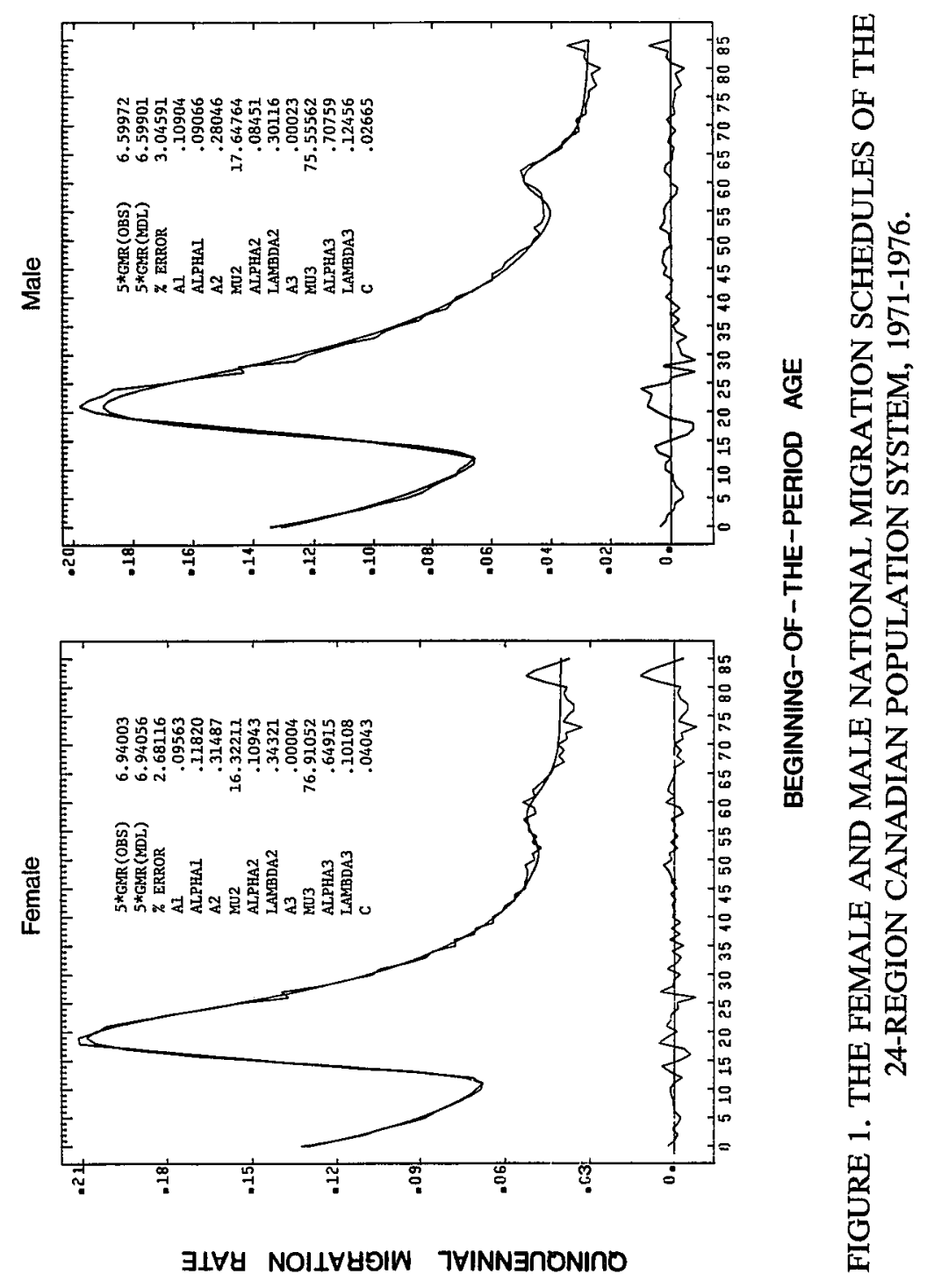
young dependents (about 6.5 percent) is reached at age 13.5 for females and 14.5 for males. These are called the low-point ages $\left(x_{\ell}+2.5\right)$.

From the low-point age, the propensity to migrate increases rapidly and reaches the highest level at age 22 for females and 24 for males; these are the high-peak ages $\left(x_{h}+2.5\right)$, which are nearly equal to $\tilde{x}_{i}$ defined in equation 4 , because the tail of the preceding component is too flat to have much effect on the location of the peak. The labour force shift, defined as $\left(x_{h}-x_{\ell}\right)$, is about 8.5 years for female and 9.5 years for males. The labour force jump, defined as $M\left(x_{h}\right)-M\left(x_{\ell}\right)$, is about 14 per cent for females and 12.5 per cent for males, representing a trebling of mobility in less than 10 years. The fact that the mobility increase in the launching

\section{TABLE 1. THE AGE OF HIGH-PEAK MOBILITY, BY SEX}

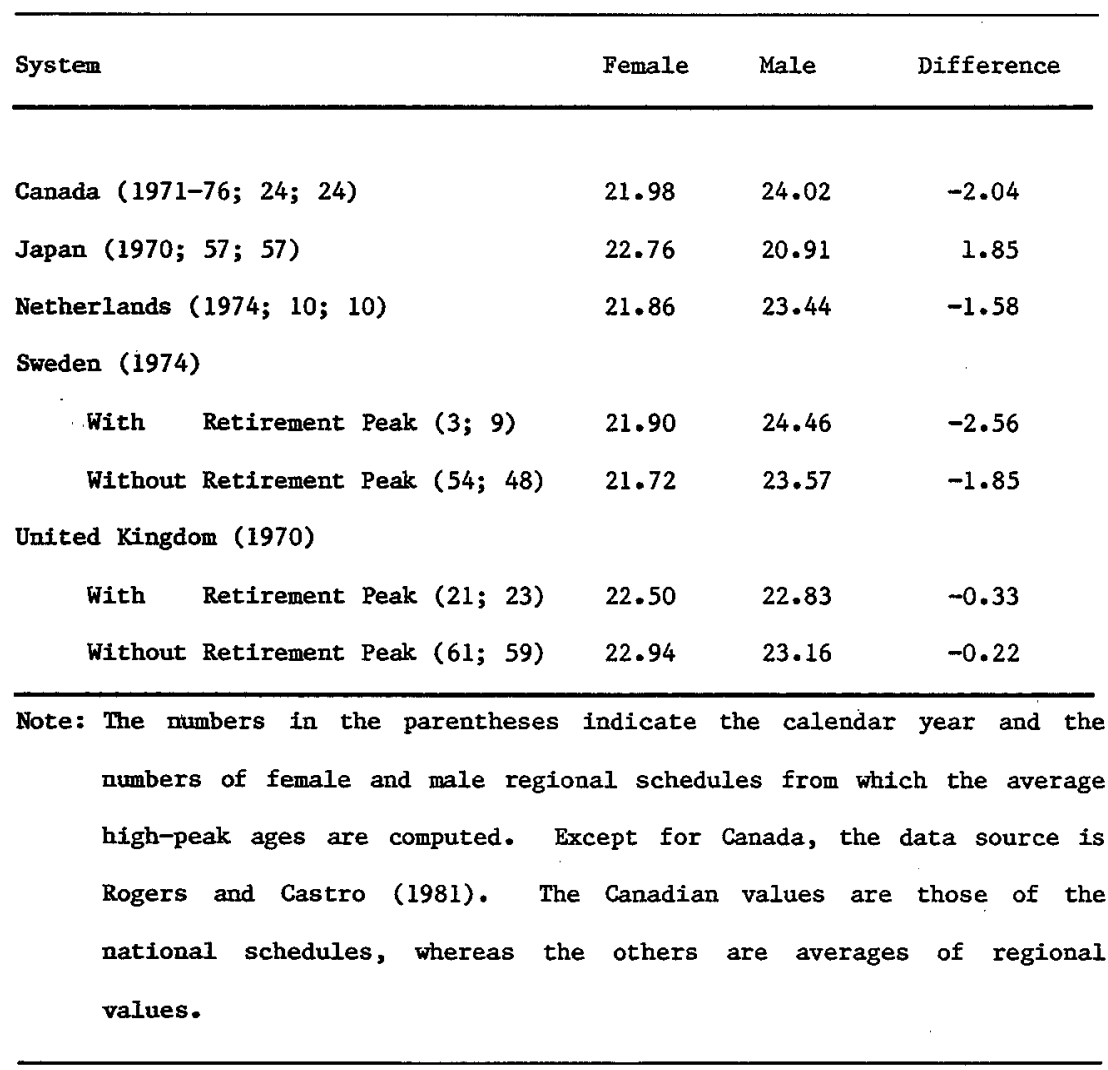


stage is faster for females than for males is indicated by the ascent parameter $\lambda_{2}(0.34$ versus 0.30$)$; whereas the central-tendency parameter $\mu_{2}$ (16.3 for females and $\mathbf{1 7 . 6}$ for males) suggests that the higher mobility level is reached earlier for females than for males.

The earlier peaking of the female mobility schedule has been found not only in Canada but also in Western European countries (Table 1). It probably results from the early entry of females into the labour force and marriage. However, Table 1 shows that the sex differential in high-peak age is very small in the United Kingdom and is reversed in Japan.

The descent from the peak, though not as fast as the ascent, is also very rapid. By age 40 , both female and male migration rates have dropped below the minimum of the young dependents. The descent parameter, $\alpha_{2}$, is greater for females $(0.11)$ than for males $(0.08)$. Table 2 suggests that the faster descent, as well as ascent, in the female mobility schedule is a rather universal phenomenon in the industrialized world.

\section{TABLE 2. THE CONTRAST IN ASCENT AND DESCENT PARAMETERS BETWEEN THE SEXES}

\begin{tabular}{|c|c|c|c|c|}
\hline \multirow[t]{2}{*}{ System } & \multicolumn{2}{|c|}{$\begin{array}{l}\text { Ascent } \\
\text { Parameter }\left(\lambda_{2}\right)\end{array}$} & \multicolumn{2}{|c|}{$\begin{array}{c}\text { Descent } \\
\text { Parameter }\left(\alpha_{2}\right) \\
\end{array}$} \\
\hline & Female & Male & Female & Male \\
\hline Canada (1971-76; 24; 24) & 0.343 & 0.301 & 0.109 & 0.085 \\
\hline Japan $(1970 ; 57 ; 57)$ & 0.350 & 0.480 & 0.151 & 0.102 \\
\hline $\begin{array}{l}\text { Netherlands }(1974 ; 10 ; 10) \\
\text { Sweden }(1974)\end{array}$ & 0.307 & 0.287 & 0.174 & 0.130 \\
\hline With Retirement Peak $(3 ; 9)$ & 0.424 & 0.416 & 0.106 & 0.093 \\
\hline $\begin{array}{l}\text { Without Retirement Peak (54;48) } \\
\text { United Kingdom (1970) }\end{array}$ & 0.537 & 0.447 & 0.127 & 0.104 \\
\hline With Retirement Peak $(21 ; 23)$ & 0.333 & 0.301 & 0.153 & 0.120 \\
\hline Without Retirement Peak ( $61 ; 59)$ & 0.327 & 0.259 & 0.151 & 0.127 \\
\hline
\end{tabular}

Note: See note to Table $I$. 


\section{TABLE 3. THE CONTRAST IN RETIREMENT PEAK AGE BETWEEN THE SEXES}

\begin{tabular}{lccc}
\hline System & Female & Male & Difference \\
\hline Canada $(1971-76 ; 24 ; 24)$ & 60.38 & 63.66 & -3.28 \\
Sweden $(1974 ; 3 ; 9)$ & 64.60 & 65.63 & -1.03 \\
United Kingdom $(1970 ; 21 ; 23)$ & 63.14 & 65.84 & -2.70 \\
\hline
\end{tabular}

Note: See note to Table 1.

Before population aging became a popular research topic, little effort was put into collecting detailed data on the mobility pattern of people beyond retirement. For example, the Canadian interregional migration data used in the monographs of George (1970), Stone (1969) and Foot (1982) indicate only that the level of migration among the elderly is very low. Our detailed data for Canada as a whole reveal a retirement peak for both females and males. The migration rate at this peak is only at the level of about 5 percent, is stronger for males than for females, and occurs at about 60.5 years for females and 63.5 years for males. Table 3 suggests that in industrialized countries generally, retirement migration takes place earlier for females than for males. This difference is probably due to the retirement of the husbands, in conjunction with the age differences between spouses.

The existence of a retirement peak is, to be sure, not a frequently observed phenomenon: instead, mobility may decrease throughout the older ages, or it may even increase with age, resulting in the so-called retirement slope. For example, in fitting their model to the data on interprovincial migration in the Netherlands, Rogers and Castro (1981) replaced the third term of their model by a simple positive exponential function because the observed migration schedules indicated an upward trend through the $70 \mathrm{~s}$ and $80 \mathrm{~s}$. Since the upward trend can also be represented by the original double exponential function with a negative value for $\alpha_{3}$, we used equation 1 to fit all the Canadian schedules. When the retirement peak and upward trend were not apparent, the third term in the equation was set to zero to ensure a fast convergence in the estimation procedure. 


\section{The Nonmetropolitan to Metropolitan Migration Pattern}

Compared with the national pattern, the essential features of the outmigration schedules from the nonmetropolitan area to the metropolitan areas, as depicted in Figure 2, are (a) the relatively low outmigration rates of young dependents (and by implication, their parents), (b) the relatively early and high peaking during the launching stage and (c) the weakness of the retirement peak. Again, the model fits the observed schedules very well, with the average error of 4.7 percent for females and 4.2 percent for males. The GMR's of about 1.1 for females and 0.97 for males indicate that the level of migration from nonmetropolitan to metropolitan areas is slightly higher for females than for males. In order to compare the shapes of nonmetropolitan schedules with those of national schedules, the standardized level parameters $\tilde{A}_{i}$ are computed according to equation 14 . The low values of $\tilde{A}_{l}$ which are 0.010 for females and 0.014 for males (compared with the national values of 0.014 and 0.017 , respectively), indicate the lack of attractiveness of the metropolitan areas to families with dependent children.

The relatively early peaking during the launching stage is indicated by relatively young high-peak ages (about 19.5 years for females and 21.5 years for males) and relatively large ascent parameters $\left(\lambda_{2}=0.62\right.$ for females and 0.44 , for males). The jumps to the high-peak - also standardized with respect to GMR - are 0.028 for females and 0.023 for males; these values are higher than for the nation as a whole $(0.020$ and 0.019 , respectively).

The retirement peak is almost nonexistent in nonmetropolitan-tometropolitan migration. For both sexes, we see only small positive residuals in the 60s over the smooth declining trend (Figure 2).

\section{Migration Pattern of the Three Most Populous Metropolitan Areas}

The lack of appeal of the largest metropolitan areas to families with young dependents, whether resident in metropolitan or nonmetropolitan areas, has been observed in many industrialized countries (Rogers, 1979; Rogers and Castro, 1981). The outmigration schedules of Montreal, Toronto and Vancouver in Figures 3 through 5 provide similar evidence relating to the Canadian population system. The values of $\tilde{A}_{1}$ are 0.015 (females in Montreal), 0.014 (males in Montreal) 0.021 (females in Toronto), 0.020 (males in Toronto), 0.019 (females in Vancouver) and 

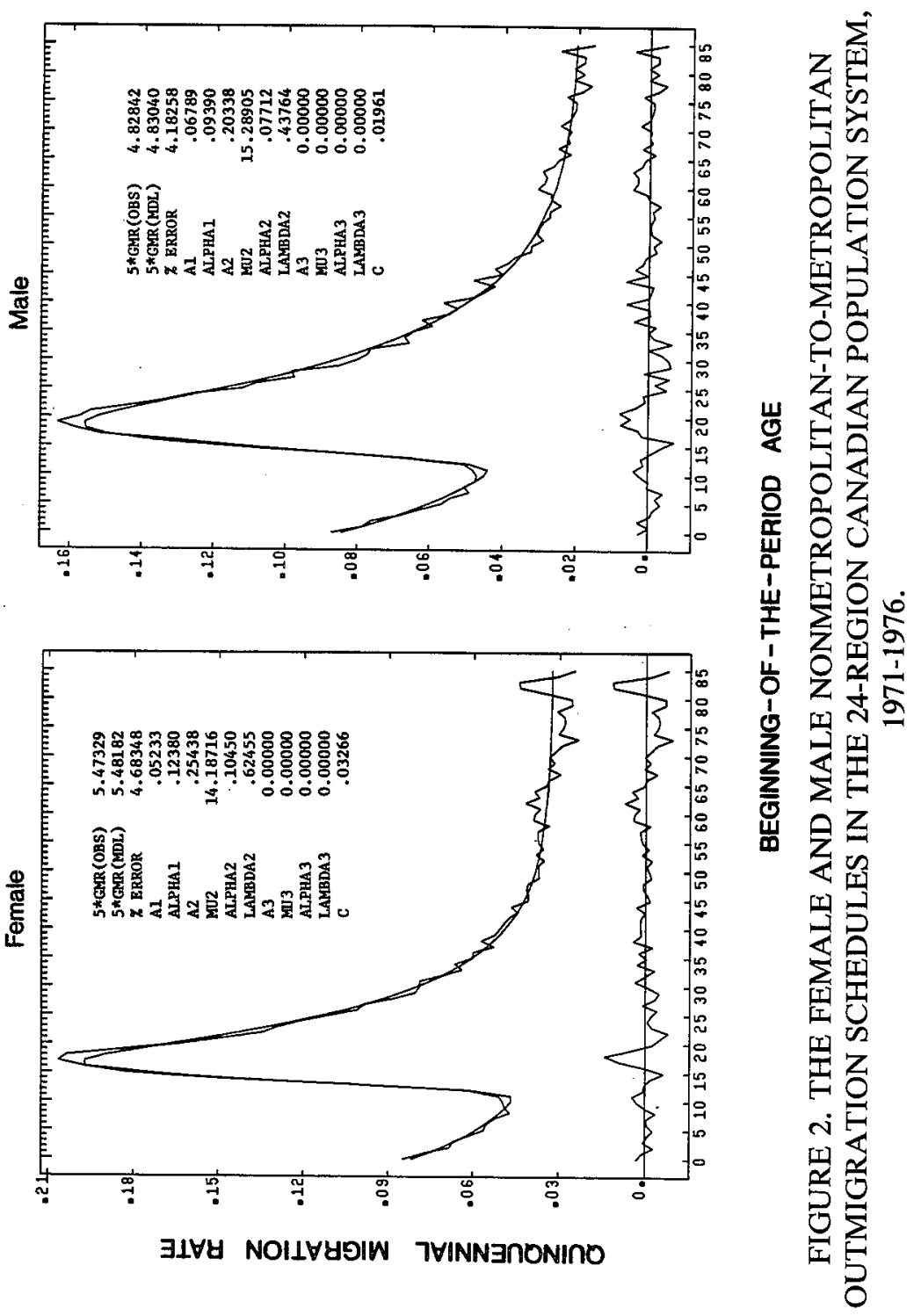
0.020 (males in Vancouver). With the exception of males in Montreal, these values are all higher than the national value of 0.014 for females and 0.017 for males. For Montreal, a clearer indication of the relatively high mobility of young children is the $\tilde{A}_{1} / \tilde{A}_{2}$ ratio, which is 0.43 for females and 0.52 for males (compared with the corresponding national figures of 0.30 and 0.39 ).

Compared to the national pattern, the migration schedules of the three largest CMA's have two further distinct characteristics: first, the low-point and the high-peak ages are both greater than the national values; second, the retirement peaks tend to be broader and more salient than the national ones. The retirement peak of Vancouver, a retirement heaven, is understandably less prominent than those of Montreal and Toronto.

The GMR values differ significantly among the three largest CMA's. For females, the values are 1.01 (Montreal), 1.50 (Toronto), and 1.72 (Vancouver); the figures for males are $0.99,1.54$, and 1.73. The corresponding interregional Unet migrationU off rates for these CMA's, both sexes combined, are -0.82 percent, -4.19 percent and -0.31 percent, which support the well-known paradox that a region with high outmigration is usually not the region with a large net loss of population in the migration transactions (Cordey-Hayes and Gleave, 1973). (In fact, the population in each of these three CMA's did increase between 1971 and 1976 because the net gain resulting from foreign migration and natural growth more than compensated for the net loss in interregional migration.)

Several systematic differences between female and male schedules that have been identified at the national level are also apparent in the three largest CMA's. For example, the low-point, high-peak and retirementpeak ages are greater in the male schedules, and the male retirement peak is more prominent than the female one.

\section{The Migration Patterns of the Remaining CMA's}

Table 4 shows that the average lifetime numbers of migrations per person (the GMR's) vary greatly, with the lowest level in the Quebec CMA (about 1.3 for both females and males), and the highest in Saskatoon (about 3.4 for females and 3.2 for males). The three western metropolitan areas with high inmigration rates (Calgary, Edmonton and Victoria) all have very high levels of outmigration (GMR $=2.5$ ), sug- 

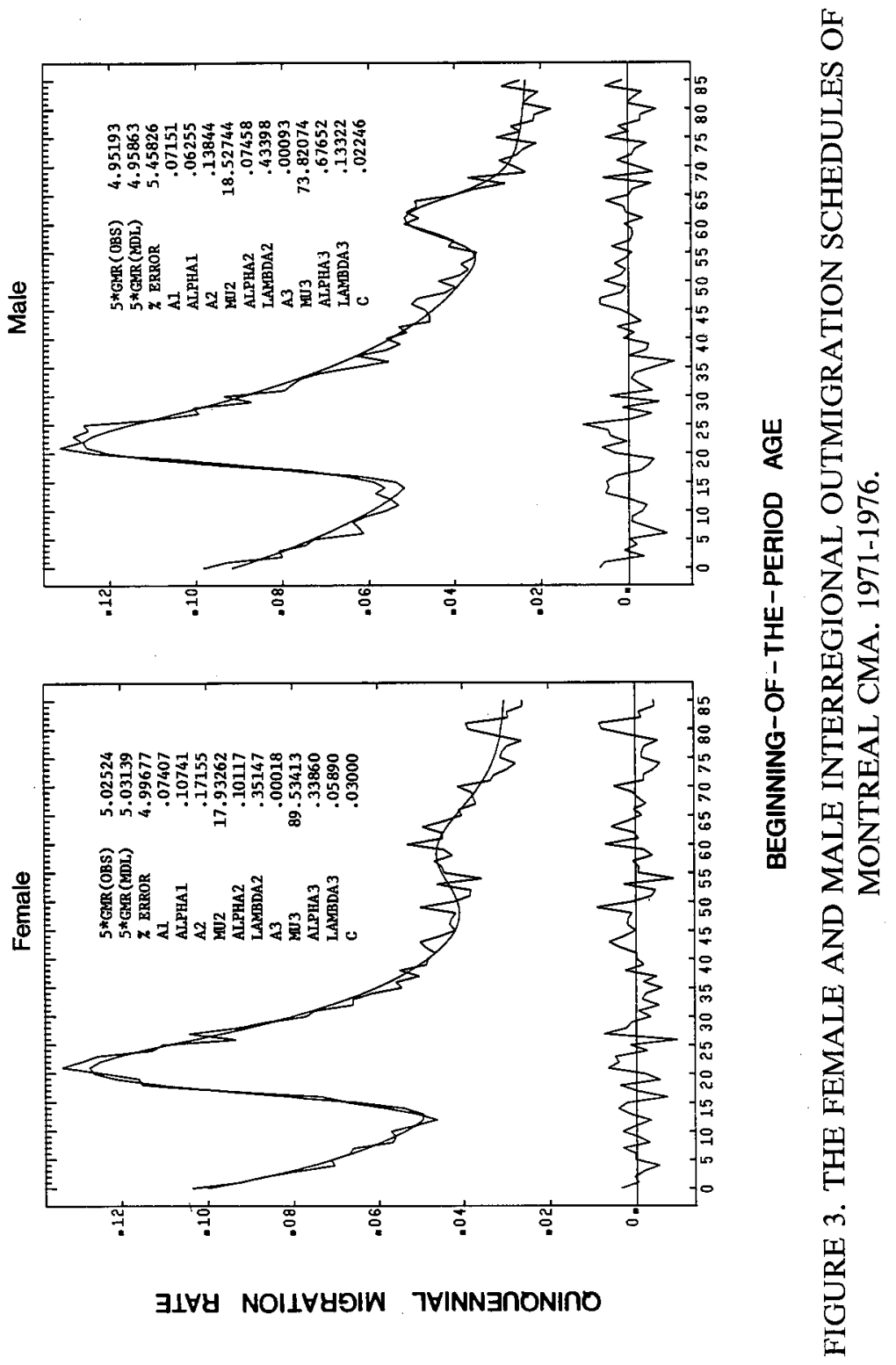
Kao-Lee Liaw and D. N. Nagnur

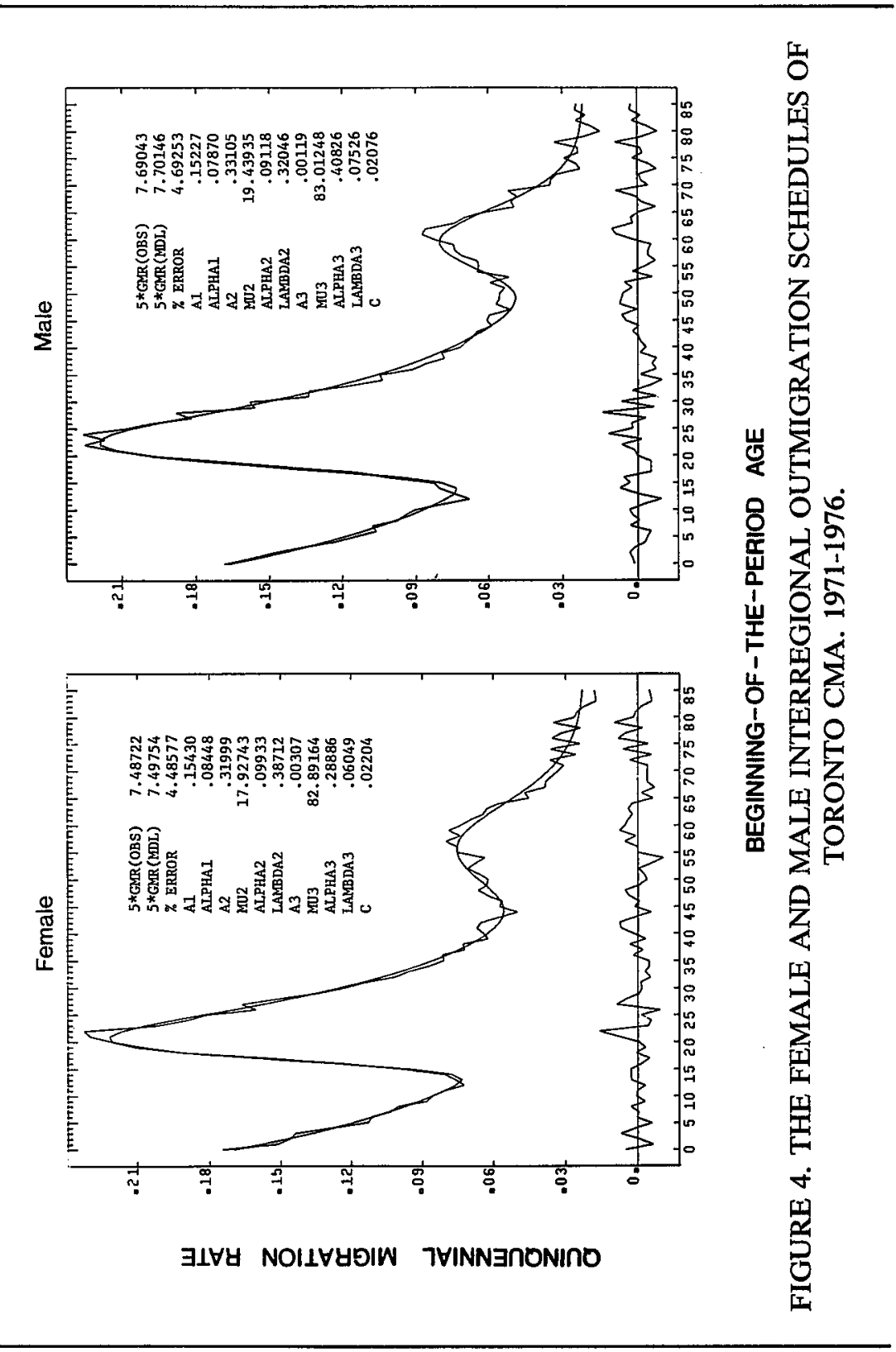



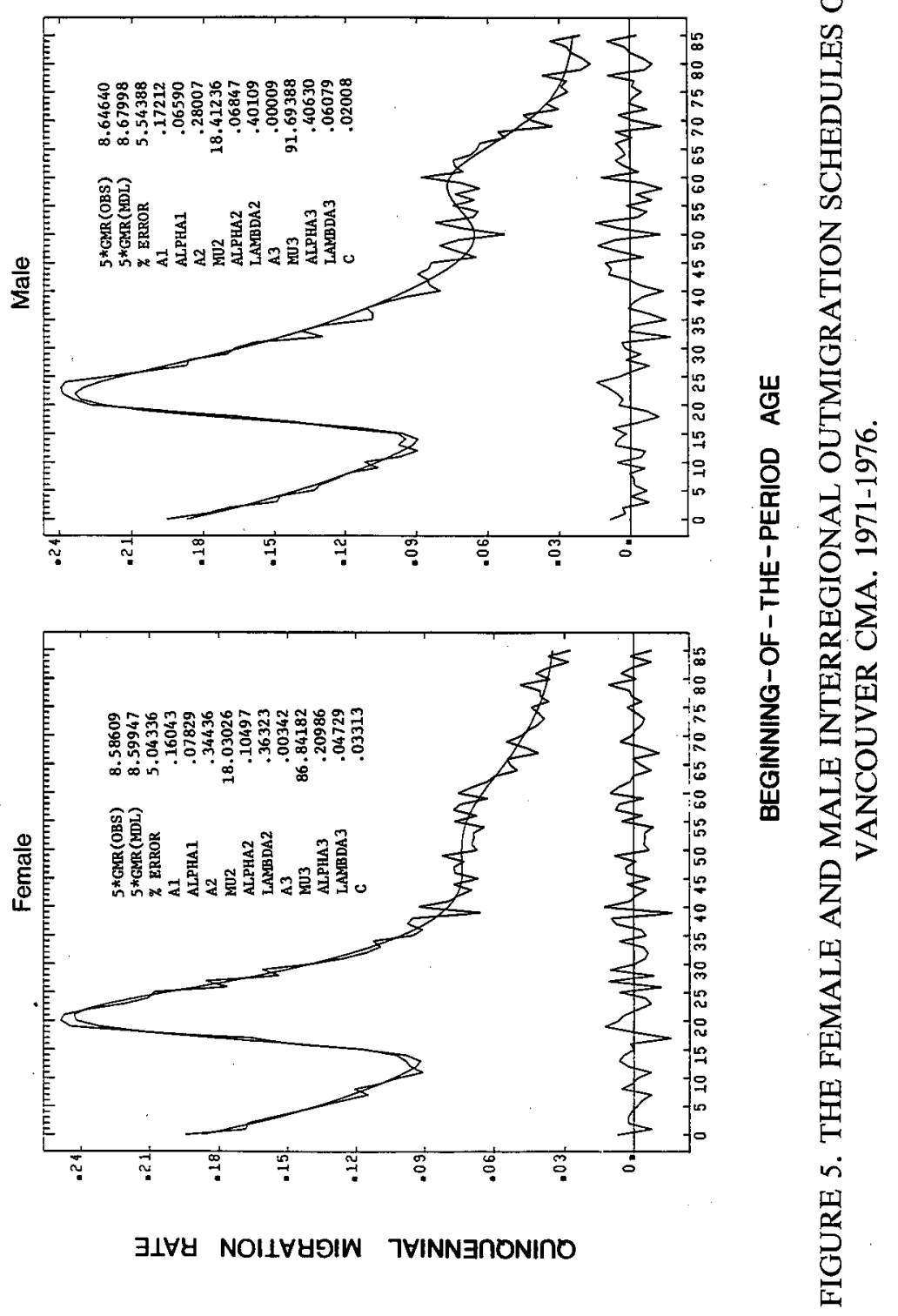
gesting that a high proportion of immigrants have failed to settle down in these booming cities.

For most of the CMA's, female and male GMR's are very similar. However, the middle columns of Table 4 shows that in most CMA's

TABLE 4. THE GROSS MIGRAPRODUCTION RATE, ITS POST LABOR FORCE PART, AND THE AVERAGE ERROR OF THE FITTED MODEL: INTERREGIONAL OUTMIGRATION SCHEDULES OF THE 24-REGION CANADIAN POPULATION SYSTEM, 1971-1976

\begin{tabular}{|c|c|c|c|c|c|c|c|}
\hline \multirow{2}{*}{\multicolumn{2}{|c|}{ Region }} & \multicolumn{2}{|c|}{ GMR } & \multicolumn{2}{|c|}{$\%$ of $\mathrm{GMR}$ in $65+$} & \multicolumn{2}{|c|}{$\begin{array}{c}\text { Average Error } \\
(\%) \\
\end{array}$} \\
\hline & & Female & Male & Female & Male & Female & Male \\
\hline 1. & St. John's & 1.75 & 1.64 & 24.5 & 18.9 & $16.5 * *$ & $20.4 *$ \\
\hline 2. & Halifax & 2.30 & 2.25 & 21.1 & 22.2 & $12.3 *$ & 12.6 \\
\hline & St. John & 1.62 & 1.55 & 20.3 & 17.3 & $19.9 * *$ & $21.1 * *$ \\
\hline & Chicoutimi-Jonquiere & 1.71 & 1.60 & 26.0 & 23.8 & $20.7 * *$ & $20.0 * *$ \\
\hline 5. & Quebec & 1.30 & 1.31 & 14.8 & 16.6 & $12.3 *$ & $13.8 * *$ \\
\hline 6. & Montreal & 1.01 & 0.99 & 14.2 & 11.5 & 5.0 & 5.5 \\
\hline 7. & Ottawa-Hull & 1.72 & 1.70 & 14.1 & 10.7 & $9.2 *$ & 8.7 \\
\hline 8. & Oshawa & 2.66 & 2.54 & 18.5 & 13.4 & $11.6 * *$ & $13.4 * *$ \\
\hline 9. & Toronto & 1.50 & 1.54 & 9.0 & 9.0 & 4.5 & 4.7 \\
\hline 10. & Hamiliton & 1.46 & 1.45 & 13.7 & 10.3 & 9.5 & 9.0 \\
\hline 11. & St.Catharines-Niagara & 1.37 & 1.31 & 13.9 & 12.0 & $12.9 *$ & $13.8 * *$ \\
\hline 12. & Kitchener & 1.91 & 1.95 & 13.5 & 10.9 & $12.6 *$ & $14.0 *$ \\
\hline 13. & London & 2.28 & 2.28 & 10.5 & 8.8 & $10.9^{*}$ & $11.6^{*}$ \\
\hline 14. & Windsor & 1.62 & 1.62 & 16.6 & 13.5 & $10.7 * *$ & $11.3^{* *}$ \\
\hline 15. & Sudbury & 2.47 & 2.39 & 21.6 & 15.4 & $12.7 * *$ & $17 \cdot 5^{*}$ \\
\hline 16. & Thunder Bay & 1.68 & 1.65 & 16.9 & 14.2 & $16.3 * *$ & $18.6 *$ \\
\hline 17. & Winnipeg & 1.78 & 1.78 & 11.5 & 7.9 & $7.6 *$ & 6.1 \\
\hline 18. & Regina & 3.02 & 2.82 & 17.4 & 10.0 & $12.4 * *$ & 11.6 \\
\hline 19. & Saskatoon & 3.35 & 3.18 & 14.0 & 10.2 & $11.0^{\star * *}$ & $13.1 * *$ \\
\hline 20. & Calgary & 2.47 & 2.53 & 12.7 & 10.4 & $8.0 *$ & $7.8 *$ \\
\hline 21 . & Edmonton & 2.44 & 2.54 & 13.6 & 11.9 & $8.9^{*}$ & 7.7 \\
\hline 22 . & Vancouver & 1.72 & 1.74 & 10.4 & 8.6 & 5.0 & 5.5 \\
\hline 23. & Victoria & 2.38 & 2.41 & 13.0 & 9.8 & $9.7 *$ & $11.1 *$ \\
\hline 24. & $\begin{array}{l}\text { Nonmetropolitan } \\
\text { Region }\end{array}$ & 1.10 & 0.97 & 12.7 & 9.5 & $4.7 *$ & $4.2 *$ \\
\hline 25 & Canada & 1.39 & 1.32 & 12.5 & 9.7 & 2.7 & 3.0 \\
\hline
\end{tabular}

*Indicates that the model without the retirement component is fitted to the observed migration schedule.

** Indicates that migration rate increases beyond the normal retirement ages. 
female mobility among those 65 and over exceeds that of males.

The information on critical ages is shown in Table 5. The ages of minimum mobility of the young dependents vary somewhat among the CMA's, centring around 14.5 years for females and 16.5 years for males. Without exception, the high-peak age is younger for females (around 23 years) than for males (around 24.5 years) in each CMA.

The average errors in the last column of Table 4 show that the observed migration schedules of the smaller CMA's are very irregular. The

TABLE 5. THE CRITICAL AGES OF THE MODEL OUTMIGRATION SCHEDULES: 24-REGION CANADIAN POPULATION SYSTEM, 1971-1976

\begin{tabular}{|c|c|c|c|c|c|c|c|}
\hline \multirow{2}{*}{\multicolumn{2}{|c|}{ Region }} & \multicolumn{2}{|c|}{ Low-point Age } & \multicolumn{2}{|c|}{ High-peak Age } & \multicolumn{2}{|c|}{$\begin{array}{l}\text { Retirement-peak } \\
\text { Age } \\
\end{array}$} \\
\hline & & Female & Male & Female & Male & Female & Male \\
\hline & St. John's & 14.4 & 13.5 & 22.1 & 24.7 & - & - \\
\hline 2. & Halifax & 15.9 & 17.5 & 22.6 & 24.4 & - & 67.0 \\
\hline 3. & St. John & 14.9 & 17.0 & 23.1 & 24.5 & - & - \\
\hline 4. & Chicoutimi-Jonquiere & 15.2 & 13.3 & 21.3 & 23.0 & - & - \\
\hline 5. & Quebec & 14.9 & 15.8 & 23.3 & 24.6 & - & - \\
\hline 6. & Montreal & 15.6 & 17.1 & 23.7 & 24.7 & 61.3 & 63.9 \\
\hline 7. & Ottawa-Hull & 15.7 & 16.3 & 23.6 & 25.4 & - & 65.7 \\
\hline 8. & Oshawa & 14.2 & 15.5 & 23.9 & 26.0 & - & - \\
\hline 9. & Toronto & 16.0 & 16.7 & 23.6 & 25.5 & 58.5 & 62.5 \\
\hline 10. & Hamilton & 14.3 & 15.8 & 23.8 & 25.1 & 54.4 & 64.4 \\
\hline 11 . & St.Catharines-Niagara & 14.6 & 14.6 & 21.4 & 22.7 & - & - \\
\hline 12. & Kitchener & 15.0 & 16.9 & 23.2 & 24.1 & - & - \\
\hline 13. & London & 16.3 & 16.8 & 23.3 & 24.8 & - & - \\
\hline 14. & Windsor & 13.6 & 14.5 & 23.2 & 24.5 & - & - \\
\hline 15. & Sudbury & 13.7 & 15.4 & 22.8 & 24.8 & - & - \\
\hline 16. & Thunder Bay & 14.8 & 14.1 & 23.2 & 26.8 & - & - \\
\hline 17. & Winnipeg & 16.3 & 17.5 & 23.2 & 25.4 & - & 63.8 \\
\hline 18. & Regina & 17.0 & 17.0 & 22.0 & 24.0 & - & 65.0 \\
\hline 19. & Saskatoon & 15.5 & 17.5 & 21.8 & 23.6 & - & - \\
\hline 20. & Calgary & 16.6 & 16.9 & 22.7 & 24.9 & - & - \\
\hline 21. & Edmonton & 16.7 & 17.6 & 22.7 & 24.8 & - & 64.4 \\
\hline 22. & Vancouver & 15.9 & 16.9 & 23.6 & 24.8 & 53.0 & 61.4 \\
\hline 23. & Victoria & 14.2 & 16.2 & 23.3 & 23.9 & - & - \\
\hline 24. & $\begin{array}{l}\text { Nonmetropolitan } \\
\text { Region }\end{array}$ & 13.6 & 13.8 & 19.5 & 21.5 & - & - \\
\hline 25 & Canada & 13.7 & 14.6 & 22.0 & 24.0 & 60.4 & 63.7 \\
\hline
\end{tabular}


irregularity is proportionately most severe in the oldest stretch of age. Because of the small numbers of individuals involved, little confidence can be placed in the shape of the right-hand tail of the fitted schedules. For example, in some smaller CMA's such as St. John's, ChicoutimiJonquière, Oshawa, Windsor and Sudbury, mobility among those 65 and over appears to be increasing with age. In fact, from the last column of Table 5 we see that only a few CMA's have the typical retiremment peaks. Among these, the retirement peak ages are about 65 years for males and younger for females.

\section{Summary and Conclusion}

As expected, the Rogers-Castro model fits the Canadian migration data quite well, especially in those cases in which migration flows involved are not too small. We have shown that Canadian migration patterns resemble those of several European countries in terms of sex differences (for example, the low-point, high-peak and retirement ages tend to be lower for females than for males), and also in the contrast between nonmetropolitan-to-metropolitan migration and the outmigration from the largest metropolitan areas (the outmigration rates of children are higher from the largest metropolitan areas than from the nonmetropolitan areas).

After examining the outmigration schedules of all 23 CMA's, we found, among other things, that the metropolitan areas differ considerably in their gross migraproduction rate, ranging from more than three lifetime migrations per person in the Saskatoon CMA, to one in the Montreal CMA; that metropolitan areas with high inmigration tend also to have relatively high outmigration; and that the migration levels at the post-labour force ages are higher for females than for males. However, due to the small size of the at-risk population, the migration pattern among those age 65 and over is highly irregular in quite a few cases. This leaves open the question of whether a normal retirement peak in migration exists in most metropolitan areas in Canada. Migration data from the 1981 census may throw light on questions such as this.

\section{Acknowledgments}

The research for this paper is supported by the Social Sciences and 
Humanities Research Council of Canada through Research Grant nos. 492-82-0001 and 410-80-0658. We extend our thanks to Byron G. Spencer for valuable suggestions and editorial help, and to Andrei Rogers for providing the estimation program.

\section{References}

Brass, W. 1974. Perspectives in population projection: illustrated by the statistics of England and Wales. Journal of Royal Statistical Society A 137:532-570.

Brass, W. and A.J. Coale. 1968. Methods of Analysis and Estimation. In William Brass, Ansley J. Coale, Paul Demeney, Don F. Heisel, Frank Lorimer, Anatole Romaniuk, Etienne van de Walle, The Demography of Tropical Africa. Princeton: Princeton University Press: 88-139.

Coale, A.J. and D.R. McNeil. 1972. The distribution by age of the frequency of first marriage in a female cohort. Journal of the American Statistical Association 67:743-749.

Coale, A.J. and T.J. Trussell. 1974. Model fertility tables: variations in the age structure of childbearing in human populations. Population Index 40:186-192.

Cordey-Hayes, M. and D. Gleave. 1973. Migration movements and the differential growth of city regions in England and Wales. Papers of the Regional Science Association 33:99-123.

Foot, D.K. 1982. Canada's Population Outlook. Toronto: James Lorimer and Co., and Canadian Institute for Economic Policy.

George, M.V. 1970. Internal Migration in Canada: Demographic Analysis. Ottawa: Dominion Bureau of Statistics.

Rogers, A. 1978. Model migration schedules: an application using data for the Soviet Union. Canadian Studies in Population 5:85-98.

Rogers, A. 1979. Migration patterns and population redistribution. Regional Science and Urban Economics 9:275-310.

Rogers, A. and L.J. Castro. 1981. Model migration schedules. RR-81-30. Laxenburg, Austria: International Institute for Applied Systems Analysis.

Rogers, A., R. Raquillet, and L.J. Castro. 1978. Model migration schedules and their applications. Environment and Planning A 10:475-502.

Spiegel, M.R. 1963. Advanced Calculus. New York: McGraw-Hill. 
Kao-Lee Liaw and D. N. Nagnur

Stone, L.O. 1969. Migration in Canada: Regional Aspects. Ottawa: Dominion Bureau of Statistics.

Received June, 1983; Revised August, 1984. 